\title{
Encuentros con Pedro Henríquez Ureña *
}

\begin{abstract}
Ue Pedro Henríquez Ureña siempre me haya parecido $\mathcal{L}$ una reencarnación de Sócrates lo he dicho mil veces: por su apariencia y presencia, por ajeno a las convenciones inútiles, por probo y fuerte y sabio, por ávido de análisis y goloso de conocer y entender al prójimo, por sediento de educar y educarse, por la valentía y sinceridad de su trato que rayaban en la impertinencia. Su conversación era una mayéutica constante: sacaba el alma afuera a sus interlocutores y desagradaba a los necios. Lo enfrentaba a uno consigo mismo. $\mathrm{Y}$ se plantaba ante el mundo con aquella visión virgínea que hacía recordar la actitud de Anacarsis Escita ante la sociedad ateniense.
\end{abstract}

Pero la mayoría de sus condiciones y cualidades más personales se quedó fuera de sus libros. Si no hubiera escrito, como Sócrates no escribió, y si como aquél sólo persistiera en el recuerdo de sus amigos, las dos siluetas se ajustarían todavía mejor, pero hubiéramos perdido la noble cosecha de sus libros. Hay, con todo, un hiato irremediable entre Pedro el hombre y Pedro el escritor. Es necesario que se diga y se sepa. De otro modo, quienes no lo conocieron de cerca no sospecharán todo su caudal. Pedro el escritor es perfecto, vive en la

* En carta dirigida al Director técnico de la Revista Iberoamericana-del 21 de enero de 1957 - el Dr. Alfonso Reyes explica las razones de orden material que le impiden escribit un artículo especial para este homenaje dedicado a Pedro Henríquez Ureña, y nos manifiesta su deseo de no estar ausente en el mismo. Por lo que nos envía estos "Encuentros con Pedro Hentíquez Ureña", ya publicados en Cuadernos (París, enero-febrero, 1955), que reproducimos agradecidos (A. A. R.). 
tradición, la gran tradición de las letras y la cultura, y ocupa un sitio único en la crítica hispanoamericana y en los fastos de la legua española. Pero Pedro el hombre era insondable, inesperado, vertiginoso y genial; y como su originalidad y su despojo de atavíos y miramientos inútiles llegaban fácilmente al cinismo (no entendido groseramente, sino según lo entiende la filosofía), también se lo pudo llamar, como al gran cínico de antaño, "el Sócrates furioso".

Esta silueta corresponde sobre todo al Pedro juvenil, el que apareció por México a comienzos del siglo XX. Llegó de Cuba a Veracruz en compañía de Carricarte. De Veracruz tuvo el acierto de traerlo el doctor Luis Lara Pardo para que colaborase en El Imparcial. Era el Pedro en rama, el Pedro heroico.

Más tarde, ya casado y con hijas, y establecido en Buenos Aires, empezó a cuidarse, a "redibujarse" un tanto por dentro y por fuera según los hábitos mundanos; se embotó su excesivo filo en el trato y aprendió a ser algo complaciente, aunque nunca haya aprendido verdaderamente a mentir. Tal era el Pedro urbano, el de la última época. La transformación, si bien se explica en parte por la edad y el cambio de estado, en buena parte se explica también por la ecología: el diálogo inevitable con los respectivos ambientes, el de México y el de la Argentina.

Cuando lo encontré por primera vez en la redacción de Savia Moderna, se me figuró un ser aparte, y así lo era. Su privilegiada memoria para los versos -cosa tan de mi gusto y que siempre me ha parecido la prenda de la verdadera educación literaria- fue en él lo que desde luego me atrajo. Poco a poco sentí su gravitación imperiosa, y al fin me le acerqué de por vida. Algo mayor que yo, era mi hermano y a la vez mi maestro. La verdad es que los dos nos íbamos formando juntos, él siempre unos pasos adelante.

En él se daba, por aquel entonces, una curiosísima mescolanza de adivinación y de inexperiencia: aquello, para la cultura; esto, para la vida.

-Debo de estar muy enfermo - me dijo un día-. Nunca tengo apetito, pero cuando se acerca la hora de comer siento como un ansia que se mitiga conforme empiezo a alimentarme. 
Era tan ordenado por dentro como desordenado por fuera. Mientras conversaba conmigo, sacaba de su lugar mis objetos de escritorio, mis libros, mis papeles, y los regaba por todas partes. Yo acudía a ponerlo todo en su sitio.

-iQué manía! —exclamaba Pedro-. Parece que te hubieran educado los jesuitas.

Yo le oponía mi "teoría semántica o jeroglífica del espacio": cada sitio tiene una significación diferente. Por ejemplo: un manuscrito a la izquierda de la mesa está aún por corregir; si se encuentra a la derecha, quiere decir que sólo falta copiarlo en limpio, etc.

- Vinieron las campañas de la juventud que he descrito en Pasado inmediato. Después de la revista Savia Moderna y la exposición organizada por el Dr. Atl, la "manifestación Gutiérrez Nájera", la Sociedad de Conferencias, la "manifestación Barreda", el segundo ciclo de conferencias en el Conservatorio, las lecciones de Antonio Caso sobre el positivismo, el Ateneo de la Juventud, las conferencias conmemorativas de 1910, la ocupación de cátedras gratuitas en la flamante Escuela de Altos Estudios, la Universidad Popular, las conferencias en la Librería General, etc. La presencia y la acción de Pedro fueron eminentes. El inventaba, él atizaba la hoguera, él participaba en todo, él marcaba rumbos. Cuando embarqué para Europa, en 1913, lo dejé ya en plena siembra. Todos los que vivieron o trabajaron a su lado llevan su huella, y mucho mentirá quien lo niegue o siquiera lo disimule.

Vivía yo en Madrid, y él radicaba ya en Minnesota, cuando, en unas vacaciones (a mediados de 1917), se me apareció vistiendo un viejo abrigo, que él, humorísticamente y no sé por qué causa, llamaba "el abrigo de José Martí". Antes de acercarse a Madrid, se detuvo un poco en Barcelona, desde donde entonces me escribía fascinado con la luminosidad, el mar y el aire. "Goza, goza el color, la luz, el oro", le contesté yo, repitiendo para él las palabras de Góngora.

Como no podía vivir ocioso, acudió conmigo al Centro de Estudios Históricos de Madrid. Entonces confeccionó su libro, de que había soltado por ahí algunas anticipaciones, sobre La versificación irregular en la poesía castellana, libro que las ediciones de la Revista de Filología Española publica- 
rían tres años después, con prólogo de don Ramón Menéndez Pidal. Esta publicación se preparó después del segundo viaje de Pedro a España, de diciembre de 1919 a principios de septiembre de 1920. El libro apareció cuando ya Pedro se hallaba de regreso en Minneapolis.

En 1917, había yo acomodado a Pedro en otro piso del mismo edificio en que yo vivía (General Pardiñas, 32). El calor era sofocante. Pedro dio en andar descalzo dentro de la casa, lo que en una ciudad marítima y tropical como Río hubiera chocado algo menos, pero que en Madrid resultaba muy extravagante.

- i Pedro ...! - -le reconvine un día suavemente.

- iAh! - me contestó con más mordacidad que candorYo no sabía que el pie era tabú.

Volvió, pues, a los Estados Unidos ("este hombre merecería vivir en un clima menos áspero", escribía Gómez de la Serna); volvió, como queda dicho, a Madrid el año de 1920, y luego a México otra vez, donde colaboró con Vasconcelos y después se alejó de él, como también lo hizo entonces Antonio Caso, y donde lo encontré a mi regreso, el año de 1924. Pero ya su mayéutica había sufrido una suerte de corregimiento por la cicuta. Le habían amargado un poco la existencia. Estaba dispuesto a alejarse, aunque siempre pensaría y trabajaría por y para México. Se casó y se fue a la Argentina, adonde lo llamaban el destino y Arnaldo Orfila Reynal.

Viví en Buenos Aires dos temporadas, mis dos Embajadas partidas por la larga estancia en el Brasil: de 1927 a 1930 , y de 1936 a 1937. Naturalmente, nuestra frecuentación era constante. Entonces me pareció que trabajaba con exceso, y había adquirido el mal hábito de hacerlo a toda hora. Ello puede haber precipitado su muerte.

En Grata compañia, al evocarlo, dije, entre otras cosas, algo que me dicido a copiar aquí, con leves retoques aclaratorios:

Estaba dotado de una laboriosidad que le era naturaleza, y ella poseía dos fases : la ostensible y la oculta. Leía, escribía y tomaba apuntes junto a la sopa, entre plato y plato, en mitad de la conversación, delante de las visitas, jugando al bridge, mientras corregía deberes escolares -i el cuitado vivió siem- 
pre uncido al pesado carro pedagógico!-, de una cátedra a otra, en el tren que lo llevaba y traía de La Plata a Buenos Aires y viceversa. A veces llegué a preguntarme si seguiría trabajando durante el sueño. $\mathrm{Y}$ es que, en efecto, bajo aquella actividad visible corría, como río subterráneo, la actividad invisible, sin duda la más sorprendente. Su pensamiento no descansaba nunca. Mientras seguía el hilo de la charla, iba construyendo, para sí, otra interior figura mental. Y, al revés, dejaba correr su charla sin percatarse, aparentemente, de las cosas que lo rodeaban.

Esta impresión era engañosa: no contaba uno con su ubicuidad psíquica. Cierta vez, por ejemplo, cuando se hallaba en España, José Moreno Villa lo llevó a ver el Escorial. Lo detuvo, en el Museo, frente al San Mauricio del Greco. Pedro habló todo el tiempo de Minnesota - el clima, la Universidad, el catedrático de literatura francesa, una profesora que estudiaba la Divina Comedia, las reuniones dominicales en la casa de algún colega- y no parecía prestar atención a lo que tenía delante. Moreno Villa volvió decepcionado. Poco después, al regreso, en un misterioso desperezo retrospectivo, Pedro dejó pasmado a Moreno Villa con un estupendo análisis del cuadro.

En apariencia, padecía las pintorescas abstracciones del sabio. En México, Caso y yo solíamos decirle que para él no existían el tiempo ni el espacio, sólo la causa. Y se hubiera creído que pasaba junto a las frivolidades sin verlas. Pero he aquí que, de pronto, le oía yo explicar, en un corro de damas porteñas, el nuevo modelo de los sombreros femeninos. $\mathrm{Y}$ lo que hacía para las pinturas y las modas, lo hacía también para la música o los deportes, con igual facilidad que para las letras, y siempre con delicadeza y elegancia. Sólo ante el cine lo vimos retroceder francamente, desencantado de las historias y no compensado por el deleite fotográfico. A menos que algunos films aparecidos en los últimos años hayan logrado convencerlo.

Y lo que es mejor todavía: el mismo proceso de elaboración hipnótica parecía operarse en su mente con respecto a los más recibidos rasgos de las costumbres y a los más arduos 
conflictos de la ética o de la política. : Ay, si se hubiera decidido a escribir todo lo que pensaba y decía!

En el entreacto de mis dos residencias platenses, todavía nos encontramos un par de ocasiones. En diciembre de 1930, él vino a pasar conmigo una temporada en Río de Janeiro, acompañado de su familia, y allí se le reunió por algunos días su cuñado Vicente Lombardo Toledano, de paso para alguna reunión obrera en Buenos Aires. Poco después, Pedro regresó a su tierra, Santo Domingo, para encargarse oficialmente de la educación pública; pero no duró en ello dos años, y de nuevo se instaló en la Argentina. En 1933, hice, en comisión diplomática, un viaje redondo entre Río y Santiago de Chile. A la ida, Pedro estaba ausente de Buenos Aires: creo entender que andaba por Córdoba; a mi retorno de Santiago, pudimos hablar unas horas. Yo iba muy de carrera y tenía que ocupar mi sitio en el Brasil para la visita del Presidente Justo.

Durante mi segunda temporada porteña, en 1936, nuestros caminos se juntaron nuevamente por menos de dos años, y disfrutamos un tiempo la compañía del llorado Enrique Díez-Canedo, entonces Embajador de España. Regresé a México el año de 1938, y aunque él, al terminar cierto curso en Harvard, se acercó hasta Cuba, Daniel Cossío Villegas y yo intentamos en vano que pasara unos días en México. Y no lo vi más, tras ocho bien contados lustros de humano comercio y comunicación.

Pero lo tengo ya junto a mí para siempre, desde aquel día de mayo, 1946, en que se derrumbó repentinamente durante uno de sus diarios viajes de Buenos Aires a La Plata. Desde ese día, no se me aleja. Hablo con él y lo interrogo. Y cuando quiero quejarme del mundo, le dirijo mensajes, como esa Carta a una sombra que distribuí entre mis amigos hace unos cuantos años.

ALFONSO REYES.

Academia Mexicana de la Lengua. 